\title{
Effect of Cordyceps militaris on Testosterone Production in Sprague-Dawley Rats
}

\author{
In-Pyo Hong*, Yong-Soo Choi, Soon-Ok Woo, Sang-Mi Han, Hye-Kyung Kim, Man-Young Lee, \\ Myung-Ryul Lee, and Richard A. Humber ${ }^{1}$ \\ National Academy of Agricultural Science, Rural Development Administration, Suwon 441-707, Republic of Korea \\ ${ }^{I}$ USDA-ARS Biological Integrated Pest Management Research Unit, Robert W. Holly Center for Agriculture \& Health, Tower \\ Road, Ithaca, NY 14853, USA
}

(Received 05 August 2011; Accepted 04 September 2011)

\begin{abstract}
Some of men have been suffered from the insufficient secretion of testosterone causing by physical factors, social and psychological factors. Testosterone is an essential steroid hormone controlling male reproductive function. Alternative medicines in plants, fungi, and insects have been studied to enhance sexuality. Cordyceps species including Cordyceps sinensis (CS) and $C$. militaris $(\mathrm{CM})$ has been used as for the enhancement of sexual functionfor hundreds of years in Far East Asian. In the present study, we determined the effect of fruiting bodies of $C$. militaris which cultured on bee drone medium (CMD) and brown rice medium (CMB) on testosterone concentration in Sprague-Dawley rats. Eighteen rats per group were housed to regular diet or diet supplemented with CMB and CDD, respectively for 4 weeks. Serum was collected from 6 rats per group. Results showed that changes of the body weight, food and water intake of the rats were not observed in this study. However, both CMB and CDD increased the serum testosterone concentration in rats. Furthermore, CMD significantly stimulated testosterone production $(p<0.05)$ compared to the control. Hence, it suggests that $C$. militaris fruiting bodymight be developed as a complementary medicine to improve sexual hormones.
\end{abstract}

Key words: Brown rice, Cordyceps militaris, Drone, Testosterone

\footnotetext{
*To whom the correspondence addressed

Sericultural\& Apicultural Materials Division, National Academy of Agricultural Science (NAAS), Seodun-dong, Gwonseon-gu, Suwon-si, Gyeonggi-do, 441-100, Korea.

Tel: +82-31-290-8461; Fax: +82-31-290-8503;

E-mail: iphong20@korea.kr
}

\section{Introduction}

The average life expectancy has continuously increased with the development of medicine. However, some of men have been suffered from the insufficient secretion of testosterone, which is caused by physical factors, social and psychological factors (Sinclair, 2000; Roscoe et al., 2001). Testosterone is an essential steroid hormone controlling male reproductive function (Saez, 1994). Alternative medicines in plants, fungi, and insects have been studied to enhance sexuality (Crimmelet al., 2001). In fact, the injection of testosterone to restore the reproductive function has been applied to treat men with insufficient testosterone secretion for decades (Huff et al., 2001). The scientific evidence related to the mechanisms or efficacy of these alternatives is scarce or often unconvincing. Recently Korean researchers have been studying the complementary medicines to improve sexual hormones in silkworm or bee drone (Ryuet al., 2010, 2011; Hong et al., 2011). Cordyceps species including Cordyceps sinensis (CS) and C. militaris (CM) has been used as Chinese traditional herb for centuries (Zhu et al., 1998). It has been reported that CS can induce the steroidogenic enzyme estradiol-17 (E2) expression in human granulosa-lutein cells (GLC) and testosterone in primary mouse Leydig cells and MA-10 mouse Leydig tumor cells (Hsu et al., 2003; Huang et al., 2004). CS is comparatively rare in nature and cannot be easily grown in culture, whereas $\mathrm{CM}$ occurs worldwide and forms fruiting bodies well. $\mathrm{CM}$ also contains higher concentration of cordycepin than CS (Yu et al., 2006). Cordycepin from C. militaris has been reported to have acute anti-inflammatory, anti-nociceptive, anti-angiogenesis and immunoregulatory activities (Kim et al., 2006).

In this study, we investigated the effect of fruiting bod- 
ies of $C$. militaris which cultured on bee drone medium (CMD) and brown rice medium (CMB), respectively on testosterone concentration in Sprague-Dawley rats.

\section{Materials and Methods}

\section{Fungal strain}

C. militaris, $\mathrm{Cmb} 233$, the mating strain between the single ascospores of $\mathrm{Cm} 186$ and $\mathrm{Cm} 209$ preserved in the Rural Development Administration, was used for fruiting body production.

\section{Materials}

C. militaris was inoculated into vegetable medium (brown rice medium) and animal medium (bee drone medium), respectively, and cultivated in National Academy Agricultural Science (NAAS). Fruiting bodies of C. militaris grown on brown rice medium $(\mathrm{CMB})$ and bee drone medium (CMD) were harvested. The harvested fruiting bodies were lyophilized and ground into powder.

\section{Animals}

Six-week-old male rats of Sprague-Dawley (SD) strain were purchased from SAMTAKO Bio Korea (Osan, Korea). Rats were housed 6 per cage in Polysulfone rat cage. The animal room was maintained at $22^{\circ} \mathrm{C}$ and $50 \%$ of room temperature and humidity under 12L: $12 \mathrm{D}$. Animals were allowed to access on Rodent diet (SAMTAKO Bio Korea) and sterilized water ad libitum. After 1 week, animals were randomly divided into three groups based on dietary categories: the control rats fed with diet, the rats fed with CMB of $250 \mathrm{mg} / \mathrm{kg} /$ day (body weight) and basal diet, and the rats fed with CMD of $250 \mathrm{mg} / \mathrm{kg}$ and basal diet. Average body weight of SD rats were $200 \sim 250 \mathrm{~g}$ at the beginning of the experiment. Each group contained 6 rats was fed on diet of various additives for 4 weeks.

\section{Testosterone concentration}

Animals were sacrificed after fasting for 16 hours before the end of experiment. The blood serum was taken at abdominal vein after incised the abdomen with ether treatment. This serum was separated by centrifuge for $15 \mathrm{~min}$ at $2500 \mathrm{rpm}$. The serum concentrations of testosterone were detected using ELISA method at the level of testosterone was analyzed at Green Cross Clinical Laboratory (Yongin, Korea).

\section{Statistical analysis}

The data from animal experiments are presented as the mean \pm S.E. and were analyzed using one way analysis of
Table 1. Body weight change (Mean \pm SD) of SD rats treated with or without Cordyceps militaris for 4 weeks

\begin{tabular}{cccc}
\hline \multicolumn{4}{c}{ Body weight $(\mathrm{g})$} \\
\hline Weeks & $\mathrm{NC}^{1)}$ & $\mathrm{CMB}$ & $\mathrm{CMD}$ \\
\hline 1 & $272 \pm 14$ & $272 \pm 10$ & $272 \pm 11$ \\
2 & $309 \pm 18$ & $305 \pm 23$ & $302 \pm 20$ \\
3 & $350 \pm 23$ & $345 \pm 30$ & $340 \pm 21$ \\
4 & $375 \pm 23$ & $364 \pm 31$ & $355 \pm 23$ \\
\hline
\end{tabular}

${ }^{1)} \mathrm{NC}$, Normal control; CMB, Fruiting body of Cordyceps militaris grown on brown rice medium, CMD, Fruiting body of Cordyceps militaris grown on bee drone medium

Table 2. Food consumption of SD rats treated with or without Cordyceps militarisfor 4 weeks

\begin{tabular}{cccc}
\hline \multicolumn{4}{c}{ Food consumption (g) } \\
\hline Weeks & NC & CMB & CMD \\
\hline 1 & 23.27 & 20.30 & 22.40 \\
2 & 25.78 & 24.83 & 26.58 \\
3 & 24.68 & 28.27 & 24.37 \\
4 & 23.58 & 23.13 & 23.54 \\
\hline
\end{tabular}

variance (ANOVA), with the differences analyzed using the Duncan's new multiple-range test. A $p$ value $<0.05$ was accepted as being a statistical significance of difference.

\section{Results and Discussion}

\section{Change in body weight}

Our analysis was focused on the comparison of change in body weights between the treatment group and the control group. There was no difference in bodyweight in rats before, during and after the experiment among rats between the treatment group and the control group (Table 1). Chang et al. (2008) reported that change of body weights in rats fed with CM supplementation was not observed.

\section{Change of feed intake}

The daily diet for the experiments was $200 \mathrm{~g}$ per cage. After 24 hours of food supply we subtract the remainder from $200 \mathrm{~g}$ per cage. Then, we divided the amount by the number of animals in the cage to obtain the quantity of feed intake. The result shows no significant difference in feed intake between the groups (Table 2).

\section{Change of water intake}

We prepared $500 \mathrm{ml}$ water the day before water intake for 
Table 3. Water consumption of SD rats treated with or without Cordyceps militaris for 4 weeks

\begin{tabular}{cccc}
\hline \multicolumn{4}{c}{ Water consumption $(\mathrm{ml})$} \\
\hline Weeks & NC & CMB & CMD \\
\hline 1 & 30.00 & 35.00 & 40.00 \\
2 & 38.33 & 35.83 & 36.67 \\
3 & 36.67 & 30.00 & 35.00 \\
4 & 38.33 & 31.67 & 31.67 \\
\hline
\end{tabular}

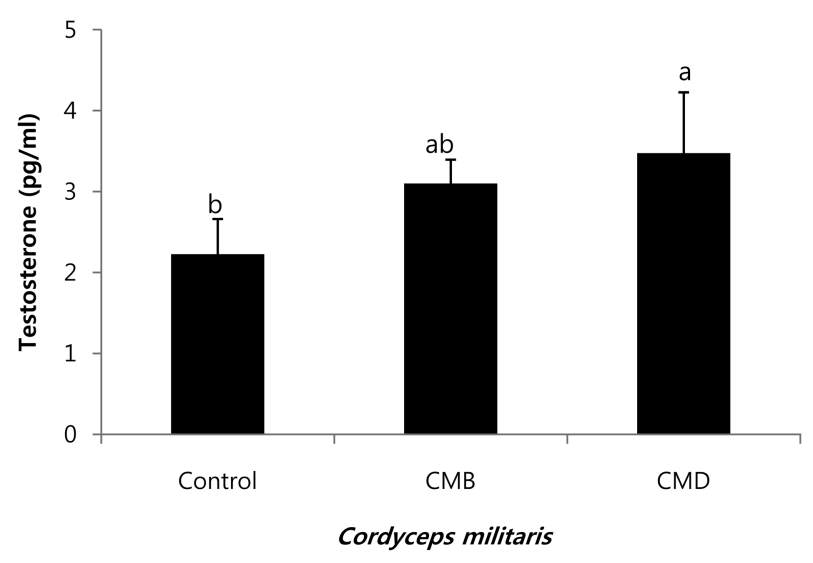

Fig. 1. Serum testosterone concentration in SD rat fed with $\mathrm{CM}$ for 4 weeks. Different letters above the bars are significantly different $(\mathrm{p}<0.05)$.

water intake quantity. The remainder of water after 24 hours from given water $500 \mathrm{ml}$ leaves the water intake quantity. The water intake quantity of each rat is value which divided the total water intake quantity per animals of cage. There was no difference in water intake among rats between the treatment group and the control group (Table 3).

\section{Change of testosterone concentrations}

We compared the testosterone secretion effect of the lyophilized powders from CMB and CMD. The result is provided in Fig. 1. The increased serum testosterone concentration was found in rats fed with CMB $(3.100 \pm$ $0.294 \mathrm{pg} / \mathrm{ml})$ and CMD $(3.475 \pm 0.750 \mathrm{pg} / \mathrm{ml})$ as compared to the control $(2.225 \pm 0.435 \mathrm{pg} / \mathrm{ml})$. Furthermore, Fig. 1 illustrates that CMD significantly stimulated testosterone production $(\mathrm{p}<0.05)$ compared to the control. We determined that the serum testosterone concentration was increased in rats fed with the fruit bodies of CM. It was reported that the sperm production is enhanced significantly by supplementation with CM mycelium even to the subfertile adult pigs (Lin et al.,2007). Our present result was in agreement with previous reports (Hsu et al., 2003; Huang et al., 2004; Chang et al., 2008).
In conclusion, the present study shows that the CM increased serum testosterone concentration in SD rats. It suggested that CMD might be developed as a complementary medicine to improve sexual hormones.

\section{Acknowledgement}

This research was supported by the research grant (PJ0067792011and PJ PJ0067552011) of Rural Development Administration (RDA) of Korea.

\section{References}

Chang Y, Jeng KC, Huang KF,Lee YC,Hou CW, Chen KH,Cheng FY, Liao JW, Chen YS (2008) Effect of CordycepsMilitarissupplementation on sperm production, sperm motility and hormones in Sprague-Dawley rats. Am J Chin Med 36, 849-859.

Crimmel AS, Conner CS, Monga M (2001) Withered Yang: a review of traditional Chinese medical treatment of male infertility and erectile dysfunction. J Androl 22, 173-182.

Hong IP, Choi YS, Woo SO, Han SM, Kim HK, Lee MR, Nam SH, HaNG (2011) Stimulatory effect of Cordycepsmilitaris on testosterone production in male mouse. Kor J Mycol 39, 148-150.

Hsu CC, Huang YL, Tsai SJ, Sheu CC, Huang BM (2003) In vivo and in vitro stimulatory effects of Cordycepssinensison testosterone production in mouse Leydig cells. Life Sci 73, 2127-2136.

Huang YL, Leu SF, Liu BC, Sheu CC, Huang BM (2004) In vivo stimulatory effect of Cordycepssinensismycelium and its fractions on reproductive functions in male mouse. Life Sci75, 1051-1062.

Huff DS, Snyder III HM, Rusnack SL, Zderic SA, Carr MC, Canning DA (2001) Hormonal therapy for the subfertility of cryptorchidism. Horm Res 55, 38-40.

Kim GY, Ko WS, Lee JY, Lee JO, Ryu CH, Choi BT, Park YM, Jeong YK, Lee KJ, Choi KS, Heo MS, Choi YH (2006) Water extract of Cordycepsmilitarisenhances maturation of murine bone marrow-derived dendritic cells in vitro. Biol Pharm Bull 29, 354-360.

Lin WH, Tsai MT, Chen YS, Hou RC, Hung HH, Li CH, Wang HK, Lai MN, Jeng KC (2007) Improvement of sperm production in subfertile boars by Cordycepsmilitarissupplement.Am J Chin Med 35: 637-647.

Roscoe WA, Barr KJ, Mhawi AA, Pomerantz DK, Kidder GM (2001) Failure of spermatogenesis in mice lacking connexin 43. BiolReprod65, 829-838.

Ryu KS, Lee HS, Kim KY, Kim MJ, Lee KG (2010) Testosterone secretion effect according to the growth stage of silkworm (Bombyx mori L.).Int J IndustEntomol 20, 75-77.

Ryu KS, Lee HS, Kang PD, Kim KY, Kim MJ, Oh HG, Kang 
PD (2011) Secretion effect of estrogen of different growth stages of silkworm (Bombyx mori L.). Int J IndustEntomol $22,17-20$.

Saez JM (1994) Leydig cells: endocrine, paracrine and autocrine regulation.Endocrine Review 15, 574-626.

Sinclair S (2000) Male infertility: nutritional and environmental considerations. Altern Med Rev 5, 28-38.

Won SY, Park EH (2005) Anti-inflammatory and related pharmacological activities of culturedmycelia and fruiting bodies of Cordycepsmilitaris.J Ethnopharmacol 96, 555-561.

Yu HM, Wang BS, Huang SC, Duh (2006) Comparison of protective effects between cultured Cordycepsmilitarisand natural Cordycepssinensisagainst oxidative damage.J Agric Food Chem 54, 3132-3138.

Zhu, JS, Halpern GM, Jones K (1998) The scientific rediscovery of a precious ancient Chinese herbal regimen: Cordycepssinensis: Part I. J AlternComplem Med 4, 289-303. 